\title{
Spectrum of Neurologic Complications in COVID-19: An Evidence-Based Review
}

\author{
Soumya Sarkar ${ }^{1}$ Puneet Khanna ${ }^{1}$ Surya K. Dube ${ }^{2}$ \\ ${ }^{1}$ Department of Anaesthesia, Pain Medicine and Critical Care, \\ All India Institute of Medical Sciences, New Delhi, India \\ 2Department of Neuroanaesthesiology, All India Institute of Medical \\ Sciences, New Delhi, India
}

\begin{abstract}
Address for correspondence Puneet Khanna, MD, Department of Anaesthesia, Pain Medicine and Critical Care, All India Institute of Medical Sciences, New Delhi 110029, India (e-mail: k.punit@yahoo.com).
\end{abstract}

\author{
Abstract \\ Keywords \\ - complications \\ - COVID-19 \\ - management \\ - neurology
}

The world is facing an unprecedented crisis due to the pandemic of current coronavirus disease 2019 (COVID-19). Coronavirus (CoVs) infections not only are always involving the respiratory tract but also possess significant neuroinvasive potential. The literature regarding neuropathogenic potential of human CoVs is sparse. Thus, the number of COVID-19-related neurologic complications is likely to be underestimated. Awareness regarding the possible spectrum of neurologic complications is essential for therapeutic decision-making and individualized treatment and thereby limiting the COVID-19related morbidity and mortality. The aim of this review is to address the neurologic manifestations of severe acute respiratory syndrome coronavirus-2 (SARS-CoV-2).

\section{Introduction}

The world is facing an unprecedented crisis due to the pandemic of current coronavirus disease 2019 (COVID-19), caused by severe acute respiratory syndrome coronavirus-2 (SARS-CoV-2). ${ }^{1}$ Since its origin in late 2019 in China, the infection was disseminated all around the globe by affecting $1,812,734$ with a fatality rate of $6.2 \%$ (World Health Organization [WHO], April 14, 2020).

The SARS-CoV-2 is an enveloped 29,903 bp single-stranded positive-sense RNA (ss-RNA) coronavirus (CoV). It is a member of the genus Betacoronavirus with an $82 \%$ identical genomic sequence with SARS-CoV. The clinical presentation is similar to the previous outbreaks of SARS-CoV in 2002 and MERS-CoV in 2012., ${ }^{2,3}$ However, reproductive number (R0), for SARS-CoV-2, is between 3.6 and 4 , indicating higher infectivity. ${ }^{4,5}$ The virus shedding usually peaks at the onset of symptoms and continues even after weeks of recovery. ${ }^{6.7} \mathrm{CoV}$ infections not only are always involving the respiratory tract but also possess significant neuroinvasive potential., ${ }^{8,9}$ However, neurologic manifestations of SARS-CoV-2 are not well addressed so far.

\section{Neuroinvasive Potential of SARS-CoV-2}

The SARS-CoV-2 infection is mediated by angiotensin-converting enzyme 2 (ACE2) receptor, which is abundantly expressed in airway epithelium, lung parenchyma, and vascular endothelium. ${ }^{10,11}$ The presence of ACE2 receptors over glial cells and neurons ${ }^{12,13}$ makes them a potential target of COVID-19. Lysosomal-related components, cathepsin L, 1-phosphatidylinositol 3-phosphate 5-kinase, also play a crucial role in viral interaction with the host cell. In vitro experiment indicates that the receptor-binding spike protein has been recognized in CD147. Both cathepsin L and CD147 are abundant in the central nervous system (CNS). ${ }^{14-17}$

SARS-CoV particles have been found in the brain of patients with SARS in 2002 and 2003..$^{18-20}$

Experimental studies on transgenic mice with SARS-CoV ${ }^{21}$ and MERS-COV ${ }^{22}$ have demonstrated that the spread of infection in the brain is possible via the olfactory nerve, and thereafter involving the thalamus and brainstem. The CoVs may first invade peripheral nerve terminals, and then affects the CNS via a synapse-connected route. ${ }^{23-25}$

The transsynaptic transfer has been well established in other CoVs, such as hemagglutinating encephalomyelitis virus 67N strain (HEV67N) $)^{24}$ and avian bronchitis virus. ${ }^{26}$

Viral antigens have been detected in the brainstem, nucleus of the solitary tract, and nucleus ambiguous in mice with intranasal inoculation of avian influenza. ${ }^{11,27}$

Such neuroanatomic interconnections indicate that the mortality of infected animals may be due to the dysfunction of the cardiorespiratory center. The neuroinvasive propensity of CoVs has been well established. Because of the high genomic similarity, it is quite likely that SARS-CoV-2 also bears a similar potential. ${ }^{11}$
DOI https://doi.org/ 10.1055/s-0040-1713017 ISSN 2348-0548.
(C)2020 Indian Society of Neuroanaesthesiology and Critical Care
License terms

() (1) $\odot \circledast$ 


\section{Host-Virus Interaction Routes}

Studies on CoVs have demonstrated retrograde neuronal transport as a viable route for viral invasion..$^{28} \mathrm{~A}$ retrograde neuronal transport via vagal from the lungs ${ }^{11}$ and enteric nervous system ${ }^{29}$ to the CNS has been postulated. However, it is yet to be established for SARS-CoV-2. The hematologic spread is a known route for systemic viral dissemination. ${ }^{30}$ Exosomal cellular transport may also be act as another mode of systemic viral dissemination. ${ }^{31}$ The SARS-CoV-2 infection leads to decrease $\mathrm{CD} 4^{+} \mathrm{T}$ cells, thereby promoting granulocyte-macrophage colony-stimulating factor and interleukin-6 (IL-6), which occasionally results in a catastrophic cytokine storm. ${ }^{32}$ No experimental data indicate the lymphatic spread of the virus. ${ }^{33}$

\section{Indirect Neurologic Complications}

CoVs generally cause respiratory and enteric diseases. ${ }^{34}$ According to the Chinese Centers for Disease Control and Prevention report, $81 \%$ of cases presented as mild pneumonia, $14 \%$ were characterized by dyspnea and hypoxia, and $5 \%$ had respiratory failure, shock, or multiorgan dysfunction. ${ }^{35}$

A recent report of Wuhan, China, described that the incidence of confusion and headache was 9 and $8 \%$, respectively, in 99 COVID-19 patients. ${ }^{36}$

A study from France has reported that the incidence of neurologic complications is $\sim 14 \%$ of the patients on admission to the intensive care unit (ICU) and 39\% of patients developed the symptoms on discontinuation of sedation and neuromuscular blockade. ${ }^{37}$

Another report of 214 patients found 36.4\% of patients with various neurologic manifestations. The neurologic symptoms can be categorized into three main areas: CNS symptoms or disease (53 [24.8\%]), peripheral nervous system (PNS) symptoms (19 [8.9\%]), and muscular symptoms, with elevated serum creatine kinase level above $200 \mathrm{U} / \mathrm{L}$ (23 [10.7\%]). In patients with CNS symptoms, the most common symptoms were dizziness (36 [16.8\%] and headache (28 [13.1\%]). In patients with PNS symptoms, the most common symptoms were hypogeusia (12[5.6\%]) and hyposmia (11 [5.1\%]). The patients with CNS symptoms had significantly lower lymphocyte, platelet counts, and higher blood urea nitrogen levels than those without CNS symptoms. ${ }^{38}$

Secondary neurologic manifestations of COVID-19 may be the result of pulmonary, renal, hepatic, and cardiovascular injury. The direct and indirect cardiotoxicity due to cytokine storm, hypercoagulability, and myocardial invasion leads to myocardial infarction, heart failure, and arrhythmias, which are primary risk factors for cerebrovascular accident. ${ }^{39}$

Mao et $\mathrm{al}^{38}$ reported that $5.7 \%$ of severely infected COVID19 patients died because of acute cerebrovascular disease. Patients with COVID-19 have high D-dimer levels and may be at higher risk of cerebrovascular diseases ${ }^{40}$

The SARS-CoV-2 infection causes hypoxemia and excessive secretion of inflammatory cytokines, which may lead to ischemic stroke. Helms et al ${ }^{37}$ have reported two patients with acute ischemic strokes.

\section{Direct Neurologic Complications}

Autopsy studies during previous SARS-CoV infections described the presence of viral RNA within the brain tissue of affected individuals. ${ }^{18}$ SARS-CoV has also been demonstrated in cerebrospinal fluid (CSF) of severely ill patients. CoVrelated meningitis, encephalitis, and acute flaccid paralysis have been reported over the years. ${ }^{41}$

The exact mechanism by which SARS-CoV-2 enters the CNS remains unclear. It may disrupt the nasal epithelium and via the olfactory bulb and retrograde transsynaptic spread affects the CNS. ${ }^{21}$ A recent experimental study suggests that the direct neuronal injury within brainstem cardiorespiratory centers may be the cause for the acute respiratory failure. ${ }^{42}$

Primary neuronal infection causes raised secretion of IL- $6,{ }^{43}$ an established mediator of the cytokine storm. Thus, neuroinflammation due to systemic dissemination can lead to encephalitis. The systemic inflammation related to metabolic derangements can also cause encephalopathy ${ }^{44}$ (-Fig. 1).

Acute necrotizing encephalopathy is a rare complication of influenza and related to intracranial cytokine storms, which result in blood-brain barrier disruption. COVID-19associated acute necrotizing hemorrhagic encephalopathy has been reported..$^{45}$

Recently the association between COVID-19 and olfactory and gustatory dysfunction has been described. The American Academy of Otolaryngology suggested that anosmia, hyposmia, and dysgeusia be included in the list of COVID-19 screening symptoms for precautionary isolation even in the absence of respiratory disease. ${ }^{46}$

\section{Postinfectious Neurologic Complications}

Of the discharged patients, 33\% have shown dysexecutive syndrome comprising inattention, disorientation, or poorly organized movements in response to command. ${ }^{37}$

It is too early to describe the long-term neurologic complications of exposure to SARS-CoV-2. The persistence of human CoVs in the CNS after the acute phase of the infection may alter host immune responses. ${ }^{41}$ Long-term sequelae may lead to increased risk for neuroinflammatory and neurodegenerative diseases. In experimental studies, CoVs have been implicated in the pathogenesis of Parkinson's disease ${ }^{47}$ acute disseminated encephalomyelitis (ADEM) ${ }^{48}$ or multiple sclerosis (MS). ${ }^{49,50}$

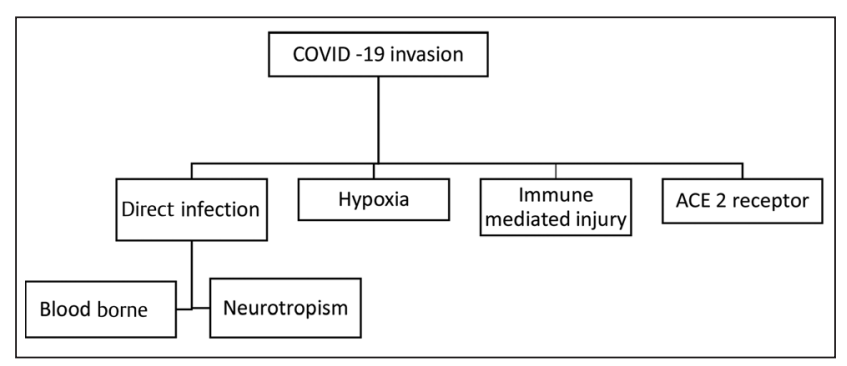

Fig. 1 Pathogenesis of nervous system invasion by coronavirus. ACE2, angiotensin-converting enzyme 2; COVID, coronavirus disease 2019. 
In $\mathrm{ADEM}^{51}$ and $\mathrm{MS}^{52}$ patients, CoV RNA has been detected in the CSF. CoV infections also have been associated with Guillain-Barré syndrome (GBS). ${ }^{33}$ Recently, a case of COVID-19 presenting with acute GBS has been reported. ${ }^{54}$

The molecular mimicry between $\mathrm{CoV}$ and myelin basic protein and direct invasion of leukocytes and other immune cells may aggravate the situation. ${ }^{55}$

\section{Neuroimaging and Other Investigations}

Magnetic resonance imaging (MRI) of the brain of the patients with unexplained encephalopathic features has not found any focal signs suggested stroke. However, enhancement in leptomeningeal spaces and bilateral frontotemporal hypoperfusion was noted in the majority of the patients. ${ }^{37}$

MRI of olfactory bulb has also been found to be inconclusive. ${ }^{56}$

Nonspecific changes were detected in electroencephalography in a majority of the patients, while a single patient had diffuse bifrontal slowing associated with encephalopathy. ${ }^{37}$

\section{Management}

Antiviral drugs (lopinavir/ritonavir, remdesivir), hydroxychloroquine, azithromycin, and other experimental agents, particularly aimed for mitigating the "cytokine storm" seen in severe cases, are currently under evaluation and being used in controlled clinical settings as they have own limitation and drug interactions (-Table 1)..$^{57}$ The U.S. Food and Drug Administration (FDA) recently approved the use of COVID-19 convalescent plasma in patients with a severe,

Table 1 Antiepileptic drug interactions with drugs for COVID-19 under trial ${ }^{57}$

\begin{tabular}{|l|l|l|l|}
\hline & ${ }^{*}$ LPV/r & RDV2 & HCLQ \\
\hline Carbamazepine & $\Re \uparrow$ & $\times$ & $\times$ \\
\hline Clonazepam & $\uparrow$ & $\leftrightarrow$ & $\leftrightarrow$ \\
\hline Clobazam & $\uparrow$ & $\leftrightarrow$ & $\leftrightarrow$ \\
\hline Diazepam & $\uparrow$ & $\leftrightarrow$ & $\leftrightarrow$ \\
\hline Ethosuximide & $\uparrow$ & $\leftrightarrow$ & $\leftrightarrow$ \\
\hline Gabapentin & $\leftrightarrow$ & $\leftrightarrow$ & $\leftrightarrow$ \\
\hline Lamotrigine & $\downarrow$ & $\leftrightarrow$ & $\leftrightarrow$ \\
\hline Levetiracetam & $\leftrightarrow$ & $\leftrightarrow$ & $\leftrightarrow$ \\
\hline Lorazepam & $\leftrightarrow$ & $\leftrightarrow$ & $\leftrightarrow$ \\
\hline Oxcarbazepine & $\sqrt{ }$ & $\Re$ & $\Omega$ \\
\hline Phenytoin & $\sqrt{ }$ & $\times$ & $\times$ \\
\hline Pregabalin & $\leftrightarrow$ & $\leftrightarrow$ & $\leftrightarrow$ \\
\hline Valproic acid & $\Uparrow$ & $\leftrightarrow$ & $\leftrightarrow$ \\
\hline
\end{tabular}

Abbreviations: HCLQ, hydroxychloroquine; LPV/r, lopinavir/ritonavir; RDV, remdesivir.

*Should not be administered without booster drug ritonavir.

$\uparrow$ Potential increased exposure of the comedication.

$\downarrow$ Potential decreased exposure of the comedication.

$\times$ Drugs should not be coadministered.

थै Potential increased exposure of COVID drug.

$\checkmark$ Potential decreased exposure of COVID drug.

$\leftrightarrow$ No significant effect.
Table 2 Potential risks associated with conventional immunosuppressant therapies ${ }^{61}$

\begin{tabular}{|l|l|}
\hline Therapy & Risk \\
\hline Intravenous immunoglobulin & $\mathrm{N}$ \\
\hline Beta-interferons & $\mathrm{N}$ \\
\hline Natalizumab & $\mathrm{N}$ \\
\hline Glatiramer acetate & $\mathrm{N}$ \\
\hline $\begin{array}{l}\text { Prednisolone: } 10-19 \mathrm{mg} / \mathrm{d} \text { monotherapy } \\
>20 \mathrm{mg} / \mathrm{d}\end{array}$ & $\mathrm{L}$ \\
\hline Methotrexate & $\mathrm{H}$ \\
\hline Azathioprine & $\mathrm{M}$ \\
\hline Mycophenolate mofetil & $\mathrm{H}$ \\
\hline Cyclophosphamide IV or oral & $\mathrm{M} / \mathrm{H}$ \\
\hline
\end{tabular}

Abbreviations: $\mathrm{H}$, high risk; IV, intravenous; L, low risk; M, moderate risk; $\mathrm{N}$, no increased risk.

life-threatening condition requiring mechanical ventilation, which has shown promising results in small preliminary uncontrolled case series. ${ }^{58}$

A multicenter, randomized controlled trial of IL-6 receptor blocker: tocilizumab is also under evaluation for severely ill patients with COVID-19.59

The use of immune-modulating therapies in patients with MS, myasthenia gravis, and other neuroimmune disorders has also become a matter of concern.

The National Multiple Sclerosis Society (NMSS) ${ }^{60}$ and the Association of British Neurologists (ABN) ${ }^{61}$ have advised for the judicious use of disease-modifying therapies and immunosuppressive drugs ( - Table 2 ).

It has been advised that patients with preexisting active neurologic disease except for myasthenia gravis or neuromyelitis optica should stop their routine medication during infection with SARS-CoV-2. Even MS patients can safely stop their immunotherapy for up to 4 weeks. However, patients on steroids ( $<20 \mathrm{mg}$ prednisolone) should continue it and may require higher doses during infection. Hydroxychloroquine and sulfasalazine can be continued safely. Human stem cell transplant and apheresis are strictly avoided. ${ }^{61}$

\section{Conclusion}

The full clinical spectrum of COVID-19 remains to be described. There is a higher propensity for SARS-CoV-2 to have a similar potential for extrapulmonary and CNS invasion. It is very difficult to identify whether these neurologic features are due to critical illness-related encephalopathy, cytokines, or the effect or withdrawal of medication, and specific to SARS-CoV-2 infection. Because of the paucity of current medical literature regarding the neuropathogenic potential of human CoVs, the number of COVID-19-related neurologic complications is likely underestimated.

Awareness regarding the possible spectrum of neurologic complications can guide therapeutic decision-making and individualized treatment and thereby limiting the COVID-19-related morbidity and mortality. 


\section{Conflict of Interest}

None declared.

\section{References}

1 Lu R, Zhao X, Li J, et al. Genomic characterisation and epidemiology of 2019 novel coronavirus: implications for virus origins and receptor binding. Lancet 2020;395(10224): 565-574

2 Coronaviridae Study Group of the International Committee on Taxonomy of Viruses. The species severe acute respiratory syndrome-related coronavirus: classifying 2019-nCoV and naming it SARS-CoV-2. Nat Microbiol 2020;5(4):536-544

3 Rothan HA, Byrareddy SN. The epidemiology and pathogenesis of coronavirus disease (COVID-19) outbreak. J Autoimmun 2020;109(February):102433

4 Pan Y,Zhang D, Yang P, Poon LL, Wang Q. Viral load of SARS-CoV-2 in clinical samples. Lancet Infect Dis 2020;20(4):411-412

5 Zou L, Ruan F, Huang M, et al. SARS-CoV-2 viral load in upper respiratory specimens of infected patients. $\mathrm{N}$ Engl J Med 2020;382(12):1177-1179

6 Bai Y, Yao L, Wei T, et al. Presumed asymptomatic carrier transmission of COVID-19. JAMA 2020;323(14):1406-1407

7 Li Q Guan X, Wu P, et al. Early transmission dynamics in Wuhan, China, of novel coronavirus-infected pneumonia. N Engl J Med 2020;382(13):1199-1207

8 Tsai LK, Hsieh ST, Chao CC, et al. Neuromuscular disorders in severe acute respiratory syndrome. Arch Neurol 2004;61(11):1669-1673

9 Zochodne DW. SARS, SIRS, and neurological disease. Arch Neurol 2004;61(11):1647-1648

10 Donoghue $\mathrm{M}$, Hsieh F, Baronas E, et al. A novel angiotensin-converting enzyme-related carboxypeptidase (ACE2) converts angiotensin I to angiotensin 1-9. Circ Res 2000;87(5):E1-E9

11 Li YC, Bai WZ, Hashikawa T. The neuroinvasive potential of SARS-CoV2 may play a role in the respiratory failure of COVID19 patients. J Med Virol 2020;1-4

12 Xia $\mathrm{H}$, Lazartigues E. Angiotensin-converting enzyme 2 in the brain: properties and future directions. J Neurochem 2008;107(6):1482-1494

13 Hamming I, Timens W, Bulthuis ML. Lely AT, Navis G, van Goor H. Tissue distribution of ACE2 protein, the functional receptor for SARS coronavirus. A first step in understanding SARS pathogenesis. J Pathol 2004;203(2):631-637

14 Ou X, Liu Y, Lei X, et al. Characterization of spike glycoprotein of SARS-CoV-2 on virus entry and its immune cross-reactivity with SARS-CoV. Nat Commun 2020;11(1):1620

15 Podvin S, Wojnicz A, Hook V. Human brain gene expression profiles of the cathepsin $\mathrm{V}$ and cathepsin L cysteine proteases, with the PC1/3 and PC2 serine proteases, involved in neuropeptide production. Heliyon 2018;4(7):e00673

16 Wang K, Chen W, Zhou Y-S. SARSCoV-2 invades host cells via a novel route: CD147-spike protein. bioRxiv 2020. Doi: 10.1101/2020.03.14.988345

17 Catepsin L. The Human Protein Atlas. Available at: https:// www.proteinatlas.org/ENSG00000172270-BSG/brain. Accessed May 20, 2020

18 Ding Y, He L, Zhang Q, et al. Organ distribution of severe acute respiratory syndrome (SARS) associated coronavirus (SARS$\mathrm{CoV}$ ) in SARS patients: implications for pathogenesis and virus transmission pathways. J Pathol 2004;203(2):622-630

$19 \mathrm{Gu} \mathrm{J}$, Gong E, Zhang B, et al. Multiple organ infection and the pathogenesis of SARS. J Exp Med 2005;202(3):415-424

$20 \mathrm{Xu} \mathrm{J}$, Zhong S, Liu J, et al. Detection of severe acute respiratory syndrome coronavirus in the brain: potential role of the chemokine $\mathrm{mig}$ in pathogenesis. Clin Infect Dis 2005;41(8):1089-1096
21 Netland J, Meyerholz DK, Moore S, Cassell M, Perlman S. Severe acute respiratory syndrome coronavirus infection causes neuronal death in the absence of encephalitis in mice transgenic for human ACE2. J Virol 2008;82(15):7264-7275

22 Li K, Wohlford-Lenane C, Perlman S, et al. Middle East respiratory syndrome coronavirus causes multiple organ damage and lethal disease in mice transgenic for human dipeptidyl peptidase 4. J Infect Dis 2016;213(5):712-722

23 Li YC, Bai WZ, Hirano N, Hayashida T, Hashikawa T. Coronavirus infection of rat dorsal root ganglia: ultrastructural characterization of viral replication, transfer, and the early response of satellite cells. Virus Res 2012;163(2):628-635

24 Li YC, Bai WZ, Hirano N, et al. Neurotropic virus tracing suggests a membranous-coating-mediated mechanism for transsynaptic communication. J Comp Neurol 2013;521(1):203-212

25 Andries K, Pensaert MB. Immunofluorescence studies on the pathogenesis of hemagglutinating encephalomyelitis virus infection in pigs after oronasal inoculation. Am J Vet Res 1980;41(9):1372-1378

26 Matsuda K, Park $\mathrm{CH}$, Sunden Y, et al. The vagus nerve is one route of transneural invasion for intranasally inoculated influenza a virus in mice. Vet Pathol 2004;41(2):101-107

27 Hadziefendic S, Haxhiu MA. CNS innervation of vagal preganglionic neurons controlling peripheral airways: a transneuronal labeling study using pseudorabies virus. J Auton Nerv Syst 1999;76(2-3):135-145

28 Dubé M, Le Coupanec A, Wong AHM, Rini JM, Desforges M, Talbot PJ. Axonal transport enables neuron-to-neuron propagation of human coronavirus OC43. J Virol 2018;92(17):e00404-e00418

29 Wong SH, Lui RN, Sung JJ. Covid-19 and the digestive system. J Gastroenterol Hepatol 2020. Doi: 10.1111/jgh.15047

30 Boehme KW, Lai CM, Dermody TS. Mechanisms of reovirus bloodstream dissemination. Adv Virus Res 2013;87:1-35

31 Alenquer M, Amorim MJ. Exosome biogenesis, regulation, and function in viral infection. Viruses 2015;7(9):5066-5083

32 Perlman S, Dandekar AA. Immunopathogenesis of coronavirus infections: implications for SARS. Nat Rev Immunol 2005;5(12):917-927

33 Louveau A, Herz J, Alme MN, et al. CNS lymphatic drainage and neuroinflammation are regulated by meningeal lymphatic vasculature. Nat Neurosci 2018;21(10):1380-1391

34 Glass WG, Subbarao K, Murphy B, Murphy PM. Mechanisms of host defense following severe acute respiratory syndrome-coronavirus (SARS-CoV) pulmonary infection of mice. J Immunol 2004;173(6):4030-4039

35 Wu Z, McGoogan JM. Characteristics of and important lessons from the coronavirus disease 2019 (COVID-19) outbreak in China: summary of a report of 72314 cases from the Chinese Center for Disease Control and Prevention. JAMA 2020;323(13):1239-1242

36 Chen N, Zhou M, Dong X, et al. Epidemiological and clinical characteristics of 99 cases of 2019 novel coronavirus pneumonia in Wuhan, China: a descriptive study. Lancet 2020;395(10223):507-513

37 Helms J, Kremer S, Merdji H, et al. Neurologic features in severe SARS-CoV-2 infection. N Engl J Med 2020;10.1056/ NEJMc2008597

38 Mao L, Jin H, Wang M, et al. Neurologic manifestations of hospitalized patients with coronavirus disease 2019 in Wuhan, China. JAMA Neurol 2020. Doi: 10.1001/jamaneurol.2020.1127

39 Baig AM, Khaleeq A, Ali U, Syeda H. Evidence of the COVID-19 virus targeting the CNS: tissue distribution, host-virus interaction, and proposed neurotropic mechanisms. ACS Chem Neurosci 2020;11(7):995-998

40 Zhou F, Yu T, Du R, et al. Articles Clinical course and risk factors for mortality of adult inpatients with COVID-19 in Wuhan, China: a retrospective cohort study. Lancet 2020;6736(20):1-9 
41 Desforges M, Le Coupanec A, Dubeau P, et al. Human coronaviruses and other respiratory viruses: underestimated opportunistic pathogens of the central nervous system? Viruses 2019;12(1):14

42 Nikolich-Zugich J, Knox KS, Rios CT, Natt B, Bhattacharya D, Fain MJ. SARS-CoV-2 and COVID-19 in older adults: what we may expect regarding pathogenesis, immune responses, and outcomes. Geroscience 2020. Doi: 10.1007/s11357-020-00186-0

43 Erta M, Quintana A, Hidalgo J. Interleukin-6, a major cytokine in the central nervous system. Int J Biol Sci 2012;8(9):1254-1266

44 Siami S, Annane D, Sharshar T. The encephalopathy in sepsis. Crit Care Clin 2008;24(1):67-82

45 Poyiadji N, Shahin G, Noujaim D, Stone M, Patel S, Griffith B. COVID-19-associated acute hemorrhagic necrotizing encephalopathy: CT and MRI features. Radiology 2020. Doi: 10.1148/ radiol.2020201187

46 Giacomelli A, Pezzati L, Conti F, et al. Self-reported olfactory and taste disorders in SARS-CoV-2 patients: a cross-sectional study. Clin Infect Dis 2020. Doi: 10.1093/cid/ciaa330

47 Fazzini E, Fleming J, Fahn S. Cerebrospinal fluid antibodies to coronavirus in patients with Parkinson's disease. Mov Disord 1992;7(2):153-158

48 Yeh EA, Collins A, Cohen ME, Duffner PK, Faden H. Detection of coronavirus in the central nervous system of a child with acute disseminated encephalomyelitis. Pediatrics 2004; 113(1 Pt 1):e73-e76

49 Murray RS, Brown B, Brian D, Cabirac GF. Detection of coronavirus RNA and antigen in multiple sclerosis brain. Ann Neurol 1992;31(5):525-533

50 Stewart JN, Mounir S, Talbot PJ. Human coronavirus gene expression in the brains of multiple sclerosis patients. Virology 1992;191(1):502-505

51 Yeh EA, Collins A, Cohen ME, Duffner PK, Faden H. Detection of coronavirus in the central nervous system of a child with acute disseminated encephalomyelitis. Pediatrics 2004; 113(1 Pt 1):e73-e76

52 Cristallo A, Gambaro F, Biamonti G, Ferrante P, Battaglia M, Cereda PM. Human coronavirus polyadenylated RNA sequences in cerebrospinal fluid from multiple sclerosis patients. New Microbiol 1997;20(2):105-114
53 Algahtani H, Subahi A, Shirah B. Neurological complications of Middle East respiratory syndrome coronavirus: a report of two cases and review of the literature. Case Rep Neurol Med 2016;2016:3502683

54 Zhao H, Shen D, Zhou H, Liu J, Chen S. Guillain-Barré syndrome associated with SARS-CoV-2 infection: causality or coincidence? Lancet Neurol 2020;19(5):383-384

55 Chew FT, Ong SY, Hew CL. Severe acute respiratory syndrome coronavirus and viral mimicry. Lancet 2003;361(9374):2081

56 Galougahi MK, Ghorbani J, Bakhshayeshkaram M, Naeini AS, Haseli S. Olfactory bulb magnetic resonance imaging in SARSCoV-2-induced anosmia: the first report. Acad Radiol 2020. Doi: $10.1016 /$ j.acra.2020.04.002

57 Liverpool COVID-19 Interactions [Internet]. Covid19druginteractions.org. 2020 [cited 15 May 2020]. Available at: http://www.covid19-druginteractions.org/. Accessed May 20, 2020

58 Shen C, Wang Z, Zhao F, et al. Treatment of 5 critically ill patients with COVID-19 with convalescent plasma. JAMA 2020;323(16):1582-1589

59 Chinese Clinical Trial Registry. A multicenter, randomized controlled trial for the efficacy and safety of tocilizumab in the treatment of new coronavirus pneumonia (COVID-19). Available at: http://www.chictr.org.cn/showprojen.aspx?proj= 49409. Accessed May 20. 2020

60 National Multiple Sclerosis Society. Disease Modifying Treatment Guidelines for Coronavirus (COVID-19). National Multiple Sclerosis Society. Available at: https://www. nationalmssociety.org/What-you-need-to-know-aboutCoronavirus-(COVID-19)/DMT-Guidelines-for-Coronavirus(COVID-19)-and. Published 2020. Accessed April 15, 2020

61 Association of British Neurologists. Association of British Neurologists Guidance on COVID-19 for people with neurological conditions, their doctors and carers. 2020. Available at: https://cdn.ymaws.com/www.theabn.org/resource/collection/ 6750BAE6-4CBC-4DDB-A684-116E03BFE634/ABN Neurology_COVID-19_Guidance_22.3.20.pdf. 